\title{
New double-stapling technique for esophagojejunostomy and esophagogastrostomy in gastric cancer surgery, using a peroral intraluminal approach with a digital stapling system
}

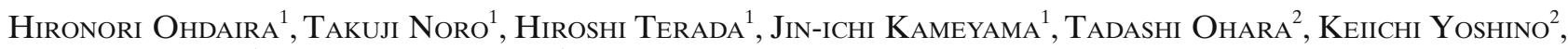 \\ MASAKi KitAJima ${ }^{1}$, and Yutaka SuZUKi ${ }^{1}$ \\ ${ }^{1}$ Department of Surgery, International University of Health and Welfare Hospital, 537-2 Iguchi, Nasushiobara, Tochigi 329-2763, Japan \\ ${ }^{2}$ Department of Gastroenterology, International University of Health and Welfare Hospital, Tochigi, Japan
}

\begin{abstract}
In the abdominal-transhiatal approach for resection of adenocarcinoma of the cardia or subcardia, and in laparoscopyassisted total gastrectomy (LATG), the use of a circular stapling device has potential problems with the placement of the purse-string suture and insertion of the anvil of the instrument. We describe a new double-stapling technique for esophagojejunostomy and esophagogastrostomy, using a peroral intraluminal approach with a digital stapling system, a flexible shaft remote-control stapler - the Surg-ASSIST and Power Circular Stapler $21 \mathrm{~mm}$ (PCS). The overtube of the flexible shaft of the PCS is prepared with a nylon tie and secured to a nasogastric (NG) tube. The flexible shaft is manually advanced down the esophagus with guidance by pulling the NG tube from the abdominal cavity side. The trocar of the flexible shaft is removed from the stump of the abdominal esophagus and connected to the anvil and they are approximated; the stapler device is then fired to form a double-stapled esophagojejunostomy and esophagogastrostomy. Our peroral intraluminal approach does not require a suturing technique, and it can make anastomosis after resection for carcinoma of the esophagogastric junction and after LATG safe and simple.
\end{abstract}

Key words Double-stapling technique (DST) · Gastrectomy · Digital stapling system

\section{Introduction}

Circular stapling devices are commonly used to form esophagojejunal or esophagogastric anastomoses after gastrectomy for proximal gastric adenocarcinoma $[1,2]$.

Offprint requests to: $\mathrm{H}$. Ohdaira

Received: November 12, 2008 / Accepted: April 18, 2009
In open surgery, esophagojejunostomy is easily performed with circular stapler methods. However, in the abdominal-transhiatal approach for resection of adenocarcinoma of the cardia or subcardia, and in laparoscopy-assisted total gastrectomy, the circular stapler technique has potential problems with the placement of the purse-string suture and the insertion of the anvil of the instrument [3-5].

We describe a new double-stapling technique for esophagojejunostomy and esophagogastrostomy, using a peroral intraluminal approach with a digital stapling system, a flexible shaft remote-control stapler, the Surg-ASSIST and Power Circular Stapler 21 mm (PCS; Power Medical Interventions, USA; Fig. 1A).

\section{Surgical technique}

With a nylon tie, the overtube of the flexible shaft of the PCS is secured to a nasogastric (NG) tube (Fig. 1B). This overtube can be used to facilitate oral insertion of the flexible shaft without difficulty.

The NG tube is manually advanced down the esophagus until the tip is seen protruding at the distal esophagus (Fig. 1C). A small opening is made in the esophagus, and the NG tube is grasped and pulled for the introduction of the flexible shaft of the PCS into the esophagus (Fig. 2A).

After transection of the duodenum and lymphadenectomy, the abdominal esophagus is divided with a linear stapler (Fig. 2B).

The flexible shaft of the PCS is rested snugly against the staple line. The nylon tie is cut, and the NG tube is detached from the flexible shaft. The overtube is released, and the head of the PCS is exposed.

The anvil of the PCS is placed at the anastomosis site of the jejunum through the open end of a Roux loop. The trocar of the flexible shaft is removed from the stump of the abdominal esophagus (Fig. 2C). The anvil 

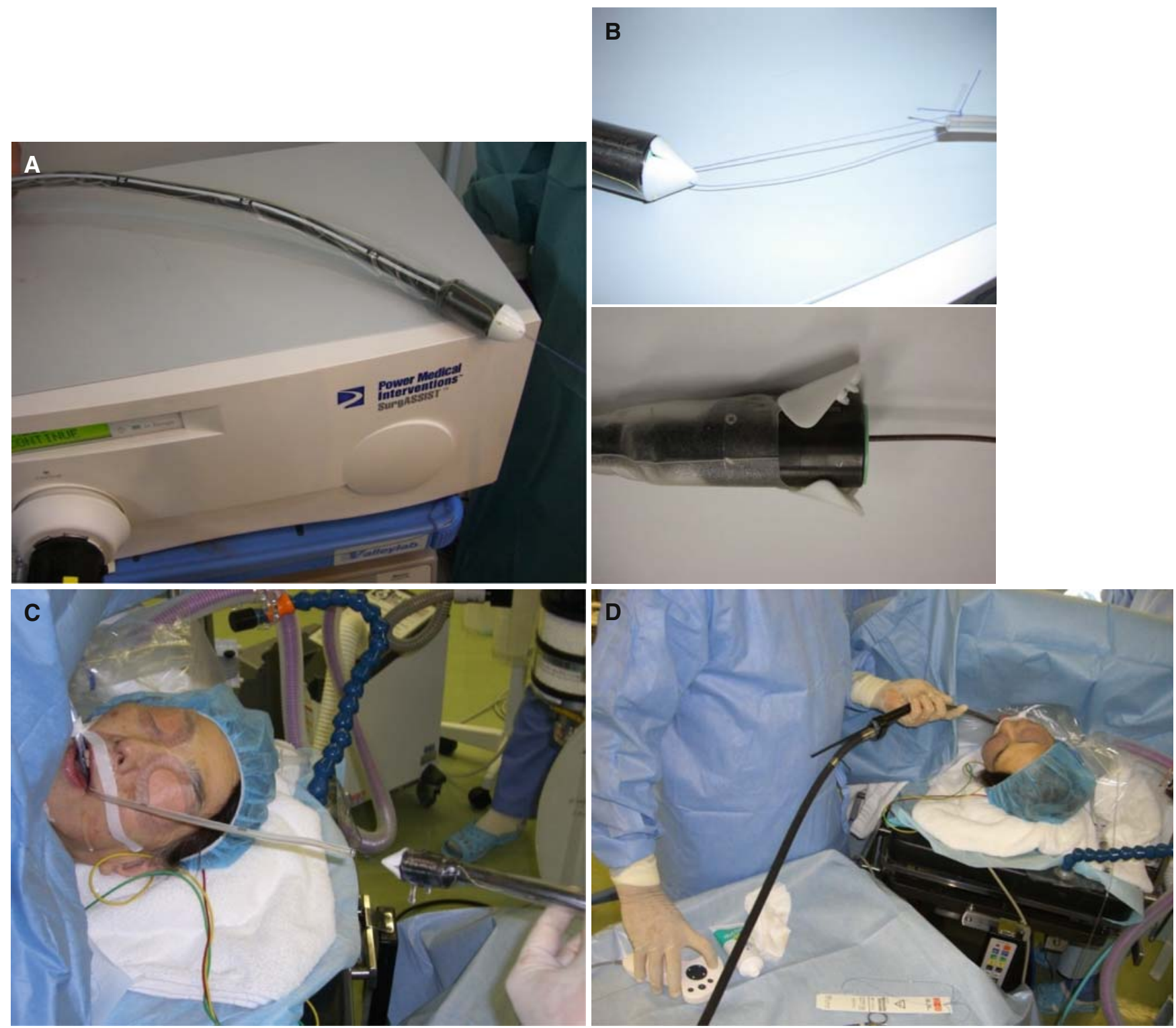

Fig. 1. A Digital stapling system (Power Medical Interventions, USA). Power console unit of the Surg-ASSIST and the flexible shaft of the Power Circular Stapler $21 \mathrm{~mm}$ (PCS) with overtube to facilitate oral insertion. B The overtube of the flexible shaft of the PCS was prepared with a nylon tie and

secured to a nasogastric (NG) tube. The head of the flexible shaft was released by cutting the nylon tie. C, D The flexible shaft of the PCS is manually advanced down the esophagus with guidance by pulling the NG tube from the abdominal cavity side

and the trocar of the flexible shaft are connected and approximated (Fig. 2D).

The remote-control stapler device is then fired to form a double-stapled esophagojejunostomy (Fig. 3A). After the anvil is removed from the open Roux loop, the flexible shaft is withdrawn, and the tissue donuts are inspected for circular integrity (Fig. 3B). The end of the Roux loop is closed with a linear stapler.

With this method, a suturing technique is not necessary.

\section{Results}

Esophagojejunostomy after total gastrectomy was performed in patient 1 (who had gastric cancer located in the lesser curvature of the upper third), and esophagogastrostomy with intrathoracic anastomosis after esophagogastrectomy was performed in patient 2 (who had adenocarcinoma located in the esophagogastric junction; Table 1) [5]. No anastomotic insufficiency was observed in either patient. 

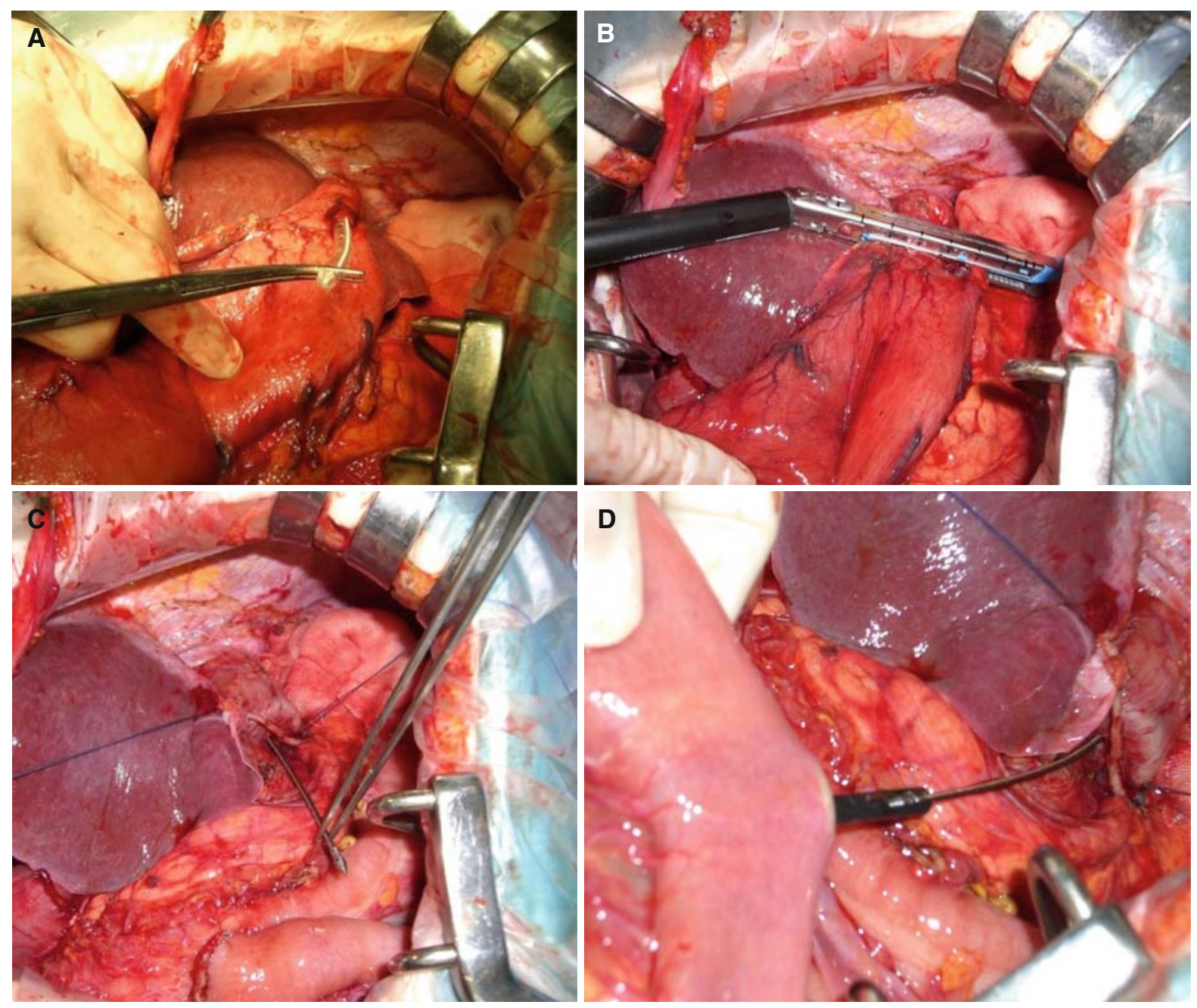

Fig. 2. A A small opening is made in the esophagus, and the NG tube is grasped and pulled for the introduction of the flexible shaft of the PCS into the esophagus. B The abdominal esophagus is divided with a linear stapler. C The trocar of the flexible shaft is removed from the stump of the abdominal esophagus. D The anvil and the trocar of the flexible shaft are connected and approximated
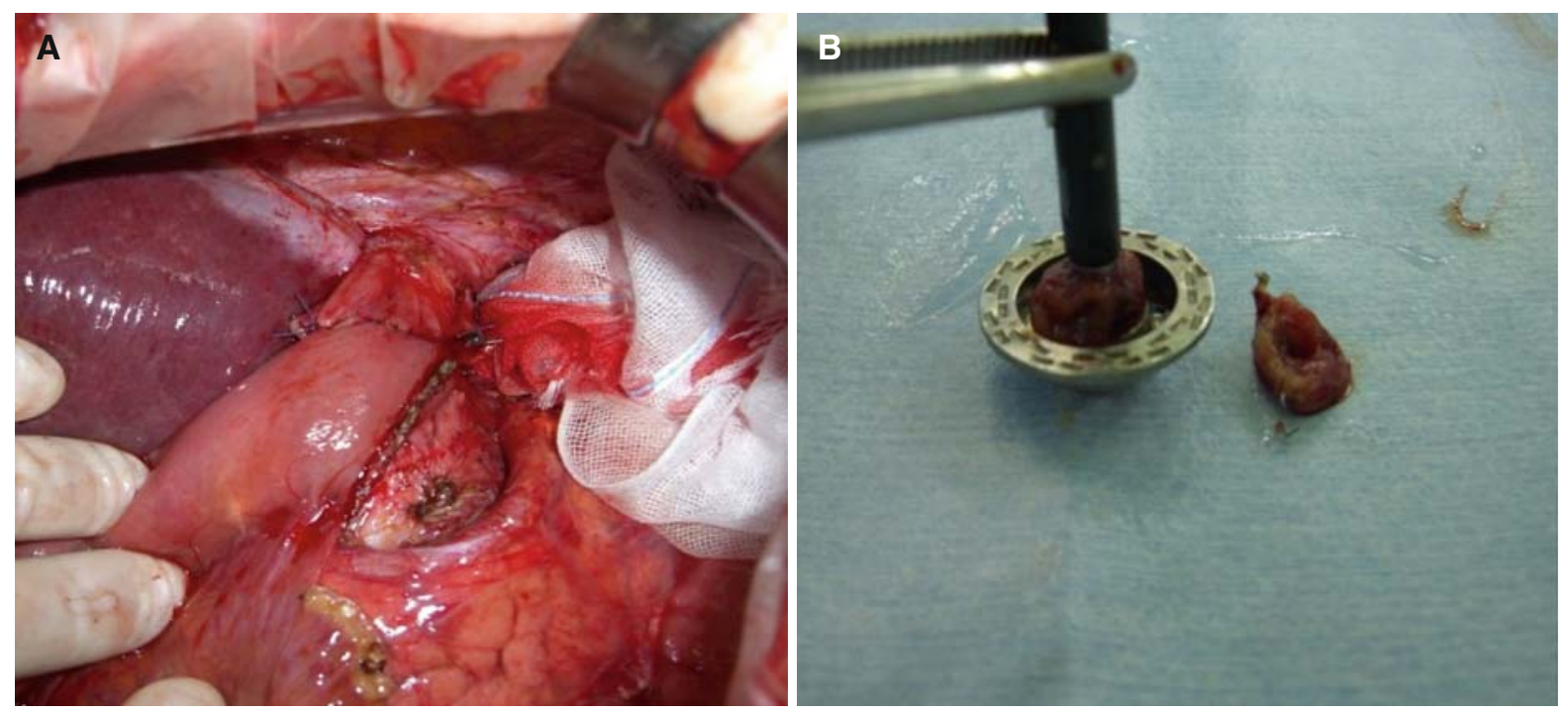

Fig. 3. A The stapler device is fired, and the double-stapled esophagojejunostomy is completed. B The tissue donuts are inspected for circular integrity 
Table 1. Operative data with our anastomotic technique

\begin{tabular}{llll}
\hline Patient & \multicolumn{1}{c}{ Extent of resection } & \multicolumn{1}{c}{ Reconstruction } & Complications \\
\hline 1 & Total gastrectomy (open surgery) & Esophagojejunostomy \\
2 & Esophagogastrectomy (laparoscopic and thoracoscopic surgery ${ }^{\mathrm{a}}$ ) & Esophagogastrostomy $^{\mathrm{b}}$ & None \\
None
\end{tabular}

${ }^{a}$ Hand-assisted laparoscopic and thoracoscopic surgery for adenocarcinoma located in the esophagogastric junction

${ }^{\mathrm{b}}$ Intrathoracic anastomosis

\section{Discussion}

Anastomosis after resection for carcinoma of the esophagogastric junction is performed in a deep and narrow working space. Under such circumstances, placing a purse-string suture and inserting the anvil of a device are difficult [4].

One reason why laparoscopy-assisted total gastrectomy (LATG) has not been widely adopted compared with laparoscopy-assisted distal gastrectomy (LADG) is that purse-string suture and anvil insertion are more difficult than with open surgery [6,7]. LADG is sometimes performed through a minilaparotomy, but this is particularly difficult, especially in obese patients. To overcome the problem of difficulty with purse-string suture placement and anvil insertion, some improvements have been reported [3, 4, 6-9].

Recently, as well as the conventional circular stapler method, functional end-to-end anastomosis or overlap anastomosis, performed with a linear stapler, has been used for esophagojejunostomy in LATG and for esophagogastrostomy in laparoscopy-assisted proximal gastrectomy (LAPG) [10, 11]. However, with the linear stapler, a greater extent of dissection and longer exposure of the abdominal esophagus are required than with the usual circular stapler method.

Peroral insertion of the flexible shaft of the SurgASSIST has been used in gastric bypass for bariatric surgery [12-14]. Martin et al. [15] reported peroral and transgastric esophageal anastomosis performed with the Surg-ASSIST for cervical esophageal anastomosis for esophageal cancer. They described this peroral intraluminal method with prograde anastomosis.

We considered the possibility that pharyngeal injury could be incurred by pushing and inserting the PCS device per os. However, we solved this problem by using the overtube secured to the NG tube with a nylon tie, and then pulling the NG tube. This "pull" technique has been used in percutaneous endoscopic gastrostomy (PEG) [16].

We were also concerned that a sufficient size of anastomosis would not be provided by a $21-\mathrm{mm}$ circular stapler. However, the PCS device seemed safer than the 25 - to $28-\mathrm{mm}$ conventional device, because this stapler device is fired only under appropriate conditions and is controlled by a digital system [13-15].
With our technique, esophagojejunostomy and esophagogastrostomy can be performed in a manner similar to the double-stapling technique used for rectal cancer surgery. We consider that the intersecting staple lines in the double-stapling technique for esophagojejuno or esophagogastric anastomosis are as safe as the intersecting staple lines in the double-stapling technique in rectal surgery under conditions of good blood flow and a tension free anastomosis. Hiki et al. [6] reported esophagogastric circular-stapled anastomosis performed with a double-stapling technique in 11 patients, and no anastomotic leakage was observed.

Another advantage of the digital stapling system we have described is that the time taken for dissection of the abdominal esophagus from the oral side may be shorter than the time needed for linear stapler procedures.

The peroral intraluminal approach with the digital stapling system can make anastomosis after resection for carcinoma of the esophagogastric junction and LATG safe and simple.

\section{References}

1. Seufert RM, Schmidt-Matthiesen A, Beyer A. Total gastrectomy and oesophagojejunostomy-a prospective randomized trial of hand-sutured versus mechanically stapled anastomoses. Br J Surg 1990;77:50-2.

2. Ikeda Y, Minagawa S, Koyanagi N, Tateishi H, Sugimachi K. Esophagojejunostomy with manual single layer suturing after a total gastrectomy for gastric cancer. J Surg Oncol 1997;66:1279.

3. Walther BS, Zilling T, Johnsson F, Staël von Holstein C, Joelsson B. Total gastrectomy and oesophagojejunostomy with linear stapling devices. Br J Surg 1989;76:909-12.

4. Guerra JP, Silva MH, dos Santos JG. An improved technique for a stapled transabdominal esophagojejunostomy. Am J Surg 1997;174:61-2.

5. Suzuki Y, Urashima M, Ishibashi Y, Abo M, Omura N, Nakada $\mathrm{K}$, et al. Hand-assisted laparoscopic and thoracoscopic surgery (HALTS) in radical esophagectomy with three-field lymphadenectomy for thoracic esophageal cancer. Eur J Surg Oncol 2005; 31:1166-74.

6. Hiki N, Fukunaga T, Yamaguchi T, Nunobe S, Tokunaga M, Ohyama S, et al. Laparoscopic esophagogastric circular stapled anastomosis: a modified technique to protect the esophagus. Gastric Cancer 2007:10:181-6.

7. Okabe H, Satoh S, Inoue H, Kondo M, Kawamura J, Nomura A, et al. Esophagojejunostomy through minilaparotomy after laparoscopic total gastrectomy. Gastric Cancer 2007;10:176-80. 
8. Parker J, Sell H Jr, Stahlfeld K. A new technique for esophagojejunostomy after total gastrectomy for gastric cancer. Am J Surg 2001;182:174-6.

9. Matsui H, Uyama I, Sugioka A, Fujita J, Komori Y, Ochiai M, et al. Linear stapling forms improved anastomoses during esophagojejunostomy after a total gastrectomy. Am J Surg 2002;184: 58-60.

10. Uyama I, Sugioka A, Fujita J, Komori Y, Matsui H, Hasumi A. Laparoscopic total gastrectomy with distal pancreatosplenectomy and D2 lymphadenectomy for advanced gastric cancer. Gastric Cancer 1999;2:230-4.

11. Uyama I, Sugioka A, Matsui H, Fujita J, Komori Y, Hatakawa Y, et al. Laparoscopic side-to-side esophagogastrostomy using a linear stapler after proximal gastrectomy. Gastric Cancer 2001; 4:98-102.
12. Waage A, Gagner M, Feng JJ. Early experience with computermediated flexible circular stapling technique for upper gastrointestinal anastomosis. Obes Surg 2003;13:88-94.

13. Liem RK, Niloff PH. Clinical experience using the computerized digital stapling system in open gastric bypass surgery for morbid obesity. Obes Surg 2003;13:837-41.

14. DeMaria EJ, McBride CL. Per-oral circular stapler in laparoscopic Roux-en-Y gastric bypass. Surg Technol Int 2005;14: $113-7$.

15. Martin ZL, Sweeney KJ, Gorey TF. Peroral and transgastric esophageal anastomosis with flexible shaft remote-control stapler (SurgASSIST). Surg Laparosc Endosc Percutan Tech 2004;14: 230-3.

16. Ponsky JL. Percutaneous endoscopic stomas. Surg Clin North Am 1989;69:1227-36. 